\title{
Experiments on High Altitude Research Management in China
}

\section{Xiaohong Yang ${ }^{1,2}$ and Yongjun Luo ${ }^{2,3 *}$}

${ }^{1}$ Department of Military Medical Geography, College of High Altitude Military Medicine, Third Military Medical University, Chongqing-400038, China ${ }^{2}$ Key Laboratory of High Altitude Medicine (Third Military Medical University), Ministry of Education, Chongqing-400038, China

${ }^{3}$ Department of High Altitude Diseases, College of High Altitude Military Medicine, Third Military Medical University, Chongqing-400038, China

\begin{abstract}
The Chinese plateau area includes all of Tibet and parts of the Qinghai, Xinjiang, Sichuan and Yunnan provinces. As reported, the plateau area in China is about $257.2 \times 10^{4} \mathrm{~km}^{2}$, which accounts for approximately $26.8 \%$ of China's land area. Until 2006, approximately 12 million people lived permanently at altitudes between 2,200 and 5,200 m on the Qinghai-Tibetan Plateau. Much scientific research regarding how to prevent and treat high altitude disease is needed in China, and it has become difficult to manage the amount of grants on high altitude research in China. This paper summarizes the experiments on high altitude research management at the Third Military Medical University in Chongqing, China. These experiments included the following: (1) improving the scientific research management system; (2) selection of quality grants to support from the Key Laboratory of High Altitude Medicine; (3) strengthening cooperation during the research process; and (4) strengthening the grant review and evaluation process. In recent years, with these high altitude research management studies, we were awarded the National Science and Technology Progress Award (first prize) in 2006, which was named "Research on the pathogenesis of and preventive measures against HAD"; we published over 1000 papers, more than 50 of which were published in SCl journals; and we received 2 national "973" projects and 1 National Technology Support Program. Additionally, we received support for 1 specialized project for the State Ministry of Health. The total value of these awards to increase the quality of high-altitude research was 49.54 million RMB.
\end{abstract}

\section{Keywords: Grant; Achievement}

\section{Introduction}

In China, high altitude is defined as 3,000 meters above sea level. As reported, the Chinese plateau area includes all of Tibet and parts of the Qinghai, Xinjiang, Yunnan and Sichuan provinces. Some references report that China's plateau area is approximately $257.2 \times 104$ $\mathrm{km}^{2}$, which accounts for approximately $26.8 \%$ of China's area [1]. Until 2006, approximately 12 million people lived permanently at altitudes between 2,200 and 5,200 $\mathrm{m}$ on the Qinghai-Tibetan Plateau [2]. Therefore, much scientific research regarding how to prevent and treat high altitude disease is needed $[3,4]$. As the funding for this area of research increased, it became difficult to manage high altitude research programs. This paper summarizes the experiments on high altitude research management at the Third Military Medical University in Chongqing China. These experiments included the following: (1) improvement of the scientific research management system; (2) selection of quality grants to support from the Key Laboratory of High Altitude Medicine; (3) strengthening cooperation during the research process; and (4) strengthening the grant review and evaluation process.

\section{Improving the scientific research management system}

The scientific research management system can ensure the smooth development of scientific research. If we do not assign importance to the management of scientific research, many research projects may run the risk of failure. Thus, scientific research management departments should pay attention to the construction of their scientific research management systems. In recent years, many rules on high altitude research management have been established, such as "Scientific management regulations," "Rules for the management of scientific research funds" and "Scientific research associations". These detailed rules were used to manage applications and the performance of projects. These rules clarified scientific collaborations and other subjects. The management of rule-based programs can ensure the success of scientific research [5].

\section{Selection of quality grants from the key laboratory of high altitude medicine}

Limited financial resources determine limitations in funding. The Key Laboratory of High Altitude Medicine relies on the Third Military Medical University for funding. Each year, approximately 10 grants are supported by the Key Laboratory of High Altitude Medicine (Third Military Medical University) by the Ministry of Education. Through regular, periodic inspection, grants showing evidence of good progress should be supported. However, projects for which there is insufficient progress should not be supported. Scientific research management entities, such as academic committees, determine which fields of study can be established. Project proposals, units and individuals determine whether an area of study is controversial. The academic committee reviews the grant with a high level of professionalism, paying attention to overall concepts. Applicants should respond to the experts' questions either orally or by revising their project. The committee forms an opinion as to whether the project has been making timely progress. For some innovations, a valuable project was funded, and low-level incremental research was rejected from the application process. The principle of innovation is based on the following criteria: the impact of the topic, the reproducibility of the studies and whether the studies have potential social and/or military value. The scientific management department should focus on providing funding to key projects to prevent unnecessary losses. Using this method, many new ideas have

*Corresponding author: Yongjun Luo, Key Laboratory of High Altitude Medicine (Third Military Medical University), Ministry of Education, Chongqing-400038, China, Tel: +86 236875 2814; E-mail: ajun-333333@163.com

Received October 28, 2014; Accepted June 24, 2015; Published June 27, 2015

Citation: Yang X, Luo Y (2015) Experiments on High Altitude Research Management in China. J Health Edu Res Dev S1: 003.

doi:10.4172/2380-5439.S1-003

Copyright: (c) 2015 Yang X, et al. This is an open-access article distributed under the terms of the Creative Commons Attribution License, which permits unrestricted use, distribution, and reproduction in any medium, provided the original author and source are credited. 
become a reality, and many outstanding young medical experts have matured professionally. With support from the Key Laboratory of High Altitude Medicine, the high altitude researcher can accumulate a research base, and the experience can prove beneficial for applying for further grants from the Chinese government.

\section{Strengthening cooperation during the research process}

Today's modern scientific and technological research studies are geared towards high-impact, focused directions that require collaboration. In scientific research, multidisciplinary collaboration is particularly important. More departmental collaboration should focus on organizing meetings, reasonably dividing worker responsibilities, signing agreements, reducing or avoiding conflicts and accelerating the research process. Quality scientific research collaboration is conducive to solving manpower, material resource, and financial issues. In 2012, the High Altitude Medicine Collaborative Creation Center was established at the Third Military Medical University. Currently, the College of High Altitude Military Medicine collaborates with Boston University, the United States National Institutes of Health, the Chinese Academy of Sciences, the Beijing Genomics Institute, Tibetan Hospital, the General Hospital of the Tibet Military Region, the 18th Hospital of the People's Liberation Army and others.

\section{Strengthening the grant review and evaluation process}

The scientific research management department should check and supervise grants every year. By adhering to a schedule, the department can help researchers solve the difficulties encountered during project implementation. When the conceptual work is completed promptly, full payment of requested funds should be given based on the goal of the research project. Programs in the process of changing, or those with potential for termination, should return their scientific research funds and should be responsible for their own accountability issues.
We have received considerable recognition in recent years with these high altitude research management studies. We were awarded the National Science and Technology Progress Award (first prize) in 2006, for the research project named "Research on the pathogenesis of and preventive measures against high altitude disease," and received 5 military (provincial and ministerial) Science and Technology Formulated national military grants criteria. Additionally, we obtained 10 national patents and 7 practical novel patents; we published over 1000 papers, more than 50 of which were published in SCI journals; and we received 2 national "973" projects and 1 National Technology Support Program and were supported on 1 specialized project for the State Ministry of Health. The total value of the awards was 49.54 million RMB.

\section{Disclosures}

All of the authors stated that they have no conflicts of interest.

\section{References}

1. Zhang Y, Li B, Zheng DA (2002) Discussion on the boundary and area of the Tibetan Plateau in China. Geographical Research. 21: 1-8.

2. Wu T, Kayser B (2006) High altitude adaptation in Tibetans. High Alt Med Bio 7: 193-208.

3. Luo Y, Zhou Q, Luo R, Yang H, Li W, et al. (2012) Building a three-dimensional high altitude medical education system to match the needs of high altitude populations. Wilderness Environ Med 23: 376-377.

4. Luo Y, Luo R, Li W, Huang J, Zhou Q, et al. (2012) High altitude medicine education in China: exploring a new medical education reform. High Alt Med Biol 13: 57-59.

5. Guo L, He G (2001) Experience Strengthening Management of Scientific Research in Military Hospital of Tableland. Hospital Administration J Chinese PLA.8: 354-355.
This article was originally published in a special issue, Etiology of Diseases, Nutrition and Human Learning handled by Editor(s). Dr. Miruka Conrad Ondieki, Kampala International University 